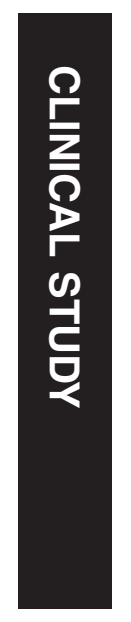

'Ophthalmology and Vision Sciences, Division of Clinical Neurosciences, B Floor, EENT Centre, Queen's Medical Centre, University of Nottingham, Nottingham, UK

${ }^{2}$ Research Design Service, East Midlands (RDS EM), School of Medicine University of Nottingham, Nottingham Health Science Partners, Nottingham, UK

${ }^{3}$ The Medical Centre, Station Avenue, Bridlington, UK

${ }^{4}$ University Hospital, Queen's Medical Centre, Nottingham and Honorary Professor of Ophthalmology, University of Nottingham, Nottingham, UK

Correspondence:

WM Amoaku, Ophthalmology and Vision Sciences, Division of Clinical Neurosciences, B Floor, EENT Centre, Queen's Medical Centre, University of

Nottingham, Nottingham NG7 2UH, UK

Tel: +44 (0)11595 15151;

Fax: +44 (0)1159627765.

E-mail:wma@nottingham.ac.uk

${ }^{5}$ Present address: The Park Hospital, Nottingham, UK.

Received: 5 March 2016 Accepted in revised form: 24 November 2016 Published online: 10 March 2017

Meeting Presentation: The material included in this manuscript was presented at the EURETINA Meeting in Nice, Sept 2015.

\section{Prevalence of age- related macular degeneration in an elderly UK Caucasian population-The Bridlington Eye Assessment Project: a cross-sectional study}

C Wilde ${ }^{1}$, A Poostchi ${ }^{1}$, RL Mehta ${ }^{2}$, HK MacNab ${ }^{3}$, JG Hillman ${ }^{3}$, SA Vernon ${ }^{4,5}$ and WM Amoaku ${ }^{1}$

\begin{abstract}
Importance There is paucity of data on prevalence and disease asymmetry of agerelated macular degeneration (AMD), particularly the earlier stages, in the UK population.

Objective and Purpose To determine the prevalence of age-related macular degeneration in an elderly Caucasian UK population.

Design Cross-sectional population study, 2002-2006.
\end{abstract}

Participants Residents in the study area of Bridlington aged 65 years and older.

Methods Full-ophthalmic examination was undertaken in 3549 participants, of eligible 6319 Caucasian population (response rate of $56 \%$ ). Non-stereoscopic Colour fundus photographs $\left(30^{\circ}\right)$ were graded masked using a modified Rotterdam Classification for 3475 $(98 \%)$ participants with gradable images. Prevalence for different AMD grades were calculated. Demographic details were analysed then integrated with the AMD gradings for full analysis. Prevalence rates for the different AMD Grades were calculated, as well as the age-specific prevalences.

Results AMD prevalence in the worst eye were $38.5 \%$ grade $0,41.4 \%$ grade $1,12.8 \%$ grade $2,2.8 \%$ grade 3 , and $4.6 \%$ grade 4 . Geographic atrophy (grade 4a) occurred in $2.5 \%$, and neovascular AMD (grade $4 \mathrm{~b}$ ) in $1.8 \%$. Prevalence increased with age such that grade 4 (advanced) AMD was $2.2 \%$ in the 65-69 years group, $15.8 \%$ for the $85-90$, and $21.2 \%$ for over 90 years. There was significant asymmetry between the two eyes of individuals with advanced AMD $(P<0.001)$, such that vision loss was unilateral. Persons with more advanced AMD grades were more likely to be dissatisfied with their vision. Conclusions Advanced AMD occurs more commonly in the UK Caucasian population than previously reported. Significant asymmetry between the two eyes occurs in individuals with unilateral advanced AMD so that visual impairment statistics do not represent true prevalence of advanced AMD. Persons with more advanced AMD were more likely to be dissatisfied with their vision. Eye (2017) 31, 1042-1050; doi:10.1038/eye.2017.30; published online 10 March 2017

\section{Introduction}

Age-related macular degeneration (AMD) is the leading cause of irreversible visual impairment in adult populations across developed countries, ${ }^{1}$ and a leading cause of global blindness. ${ }^{2}$ With the increasing shift towards ageing populations, its prevalence is expected to increase significantly. AMD represents the advanced end of pathological changes within the ageing macula. The earliest features referred to as age-related maculopathy (ARM), consist of yellow sub-retinal pigment epithelial (RPE) deposits (drusen), some types of which have long been an established risk factor for the development of AMD since first described by Gass. ${ }^{3}$ Focal alterations of physiological pigmentation of the RPE also form part of the spectrum of ARM. ${ }^{4,5}$ 
The presence of drusen, with associated areas of focal hypopigmentation or hyperpigmentation of the RPE, have come to signify increased risk of progression to advanced stages of AMD, and associated potential for visual loss. 4,5 The two main phenotypes of AMD are geographic atrophy (GA), characterised by atrophy of the choriocapillaris, overlying RPE and photoreceptors, and neovascular AMD (nAMD), signalled by the development of choroidal neovascular membranes (CNV) into the sub-RPE or subretinal spaces. There are currently no proven treatments for dry AMD. Despite treatments with anti-vascular endothelial growth factor (anti-VEGF) therapies for nAMD, the number of individuals in the UK with sight loss secondary to AMD is expected to rise from 223224 in 2010 to 291982 by $2020 .^{6}$

Several population based studies from across the world have reported prevalence estimates for ARM/AMD, ${ }^{7-16}$ including developed countries such as Australia, 7,8 The United States, ${ }^{9}$ a number of European studies, ${ }^{10-16}$ and a few from Asia and elsewhere. ${ }^{17-20}$ Heterogeneity exists in reported prevalence rates between populations, reflecting either genuine differences, offering potential insight into genetic and environmental causes of AMD, or different study designs. Variations in age groups, photographic methods utilised (field size, stereoscopic/ non-stereoscopic, or mydriatic/non-mydriatic photographs) along with variations in grading procedures and definitions may impact the reported prevalence. A recent meta-analysis of AMD prevalence across populations of European ancestry confirmed significant heterogeneity in prevalence rates between studies. ${ }^{21}$ Although several publications exist on AMD prevalence in the UK, there remains a paucity of data from population studies from this country. Some UK prevalence estimates were based on data from registration of visual impairment ${ }^{22}$ with associated inherent shortcomings. Under-certification is reported; ${ }^{23}$ while patients with bilateral visual impairment may be registered, persons with early ARM, asymptomatic, unilateral, or eccentric AMD, where bilateral visual acuity (VA) is not reduced go unrecorded. Furthermore, registration is dependent on patient consent. Other estimates are based on pooled findings from studies undertaken in various white populations of shared European ancestry in the UK and elsewhere. 6,24,25 Population prevalence studies of AMD in the UK with large sample sizes are limited,,$^{26-29}$ and much of the available data are old. ${ }^{27,30}$ Furthermore, information provided on the early stages of ARM is sparse. The study by Evans et al ${ }^{26}$ involved a large population; however, participation was restricted to individuals aged $\geq 75$ years and the study adopted community screening for reduced vision for case detection. A publication by Ngai et al ${ }^{31}$ included only male subjects aged 65-83 years, as part of a longitudinal cohort, with potential selection bias from a healthy survivor effect. Other studies adopted non-standard grading definitions, making comparisons to other reports difficult. ${ }^{28}$ The EUREYE study included one UK centre in Northern Ireland, which contributed 634 participants. ${ }^{11}$

A recent systematic review, seeking to provide reliable estimates on AMD prevalence in populations of European ancestry $^{21}$ underpins the need for a more robust population based measure to provide information on asymptomatic and asymmetric disease along with information on ARM, allowing more adequate healthcare planning for the UK. This manuscript presents data on the prevalence of ARM and AMD in persons 65 years of age or older in a UK Caucasian population.

\section{Methods}

\section{Study design}

The Bridlington Eye Assessment Project (BEAP) is a single centre population based prevalence study, with the primary objective to investigate the utility of screening for eye disease in an elderly population $\geq 65$ years, using clinical examination by trained optometrists and digital imaging technology. The primary ophthalmic diseases studied were AMD, cataract, and glaucoma. Bridlington, a coastal town in Yorkshire, UK, was chosen because it included a relatively stable predominantly Caucasian elderly population with little migration. The study received approval from the local ethics committee (Scarborough and North East Yorkshire Local Ethics Research Committee; Ref No. PB/RH/02/288), and its methodology adhered to the tenets of the Declaration of Helsinki. A detailed description of the study design has been reported elsewhere. ${ }^{32}$ Study recruitment occurred between 5/11/2002 and 29/03/2006.

All participants were interviewed, in person, by a trained research nurse using structured questionnaire, and examined by one of four specially trained optometrists with structured proforma completed by the research staff. All participants were asked if they were subjectively happy with their current self-perceived level of vision using a simple categorical grading of 'satisfied' or 'dis-satisfied'.

Non-stereoscopic mydriatic fundus photography was performed with a Topcon fundus camera (model TRC NW6S) and a Nikon 10 megapixel camera. Each eye had a $30^{\circ}$ colour fundus photograph taken centred on the macula. Further details of Methodology are provided in Online Supplementary. 


\section{Photographic grading}

Photographs of right and left eyes were graded masked by a single ophthalmologist (CW) who was trained in image grading at the Central Angiographic Reading Facility (CARF), Belfast, using definitions and grids as described in the International Classification System for AMD. ${ }^{33}$ In this system a circle with diameter of $6000 \mu \mathrm{m}$ is centred on the fovea and features of ARM/AMD recorded. The grid consists of three concentric circles with radii of 500,1500, and $3000 \mu \mathrm{m}$, with four radial lines angled at $45^{\circ}$ and $135^{\circ}$ dividing the grid into nine subfields. Drusen were categorised on the basis of their size, homogeneity, and outline. ${ }^{33}$ Pigmentary irregularities were classified as hyperpigmentation, hypopigmentation, or both. GA was defined as a sharply demarcated area of RPE loss, of at least $175 \mu \mathrm{m}$ in diameter and roughly round or oval in shape, with at least two of the following features: scalloped edges, visible choroidal vessels that are more prominent than in the surrounding areas and well defined margins inkeeping with the clarity of the fundus photograph. nAMD was assigned if there were any of the following features within the grid: definite RPE detachment, haemorrhagic or serous, and/or subretinal or sub-RPE haemorrhages unassociated with any other vascular lesion and/or intraretinal, subretinal or sub-RPE glial tissue, and/or subretinal or sub-RPE neovascular membrane as characterised by grey/yellowish discolouration. If any of these features occurred directly adjacent to and contiguous with the optic disc, a grade of peripapillary CNV (PPCNV) was assigned. When GA and nAMD coexist in the same eye, the eye was graded as nAMD. If doubt existed as to whether a lesion was AMD or other pathology such as diabetic retinopathy, pathological myopia, chorioretinitis, or laser burns, then it was not graded as AMD. All images graded as GA were specifically reviewed to ensure that none had a recorded history of diabetic retinopathy or previous macular laser. In addition, frequent sessions of simultaneous grading with a retinal specialist (WMA) were performed to maintain reproducibility.

All questionable lesions, and eyes that were graded as GA, nAMD, or PPCNV were reviewed and scrutinised by WMA. Any differences in opinion were sent to CARF for grading. One in ten ( 1 in 10) randomly selected right eye images were sent to the CARF for secondary masked grading by certified graders. Any differences between CW and CARF were adjudicated by WMA. The signs of ARM/AMD were stratified using the modified Rotterdam grading system (Table 1 ), and recorded as one of five exclusive stages (0-4) to facilitate statistical analysis. 5,34 Each eye was graded separately, and the final grade assigned to each participant was that of the worse
Table 1 Modified Rotterdam AMD Grading Scale

\begin{tabular}{|c|c|}
\hline Grade & Description \\
\hline $0 \mathrm{a}$ & Normal-no signs of AMD at all \\
\hline $\mathrm{Ob}$ & $<10$ hard drusen $<63 \mu \mathrm{m}$ in size \\
\hline $1 \mathrm{a}$ & $\geq 10$ hard drusen or any soft distinct drusen $\geq 63 \mu \mathrm{m}$ \\
\hline $1 b$ & $\begin{array}{l}\text { Pigmentary abnormalities only, or with hard drusen } \\
63 \mu \mathrm{m} \text { in size, no soft drusen }\end{array}$ \\
\hline $2 \mathrm{a}$ & $\begin{array}{l}\text { Soft distinct indistinct drusen } \geq 125 \mu \mathrm{m} \text { in size or reticular } \\
\text { drusen only }\end{array}$ \\
\hline $2 b$ & $\begin{array}{l}\text { Soft distinct drusen } \geq 63 \mu \mathrm{m} \text { in size with pigmentary } \\
\text { abnormalities }\end{array}$ \\
\hline 3 & Soft indistinct drusen $\geq$ with pigmentary abnormalities \\
\hline $4 \mathrm{a}$ & Geographic atrophy \\
\hline $4 b$ & Neovascular AMD \\
\hline $4 \mathrm{c}$ & Peri-papillary neovascular CNV \\
\hline 7 & Other macular disease \\
\hline 8 & No image available \\
\hline 9 & Ungradable image \\
\hline
\end{tabular}

or only eye. Grade 4 AMD was classified as advanced, grade 3 as intermediate, and grades 1-2 as early AMD.

\section{Statistical methods}

Statistical analysis was performed using Stata 12.0 (StataCorp, College Station, TX, USA) and SPSS v.22 (IBM Corp. Armonk, NY, USA). Continuous outcomes were compared between participants with gradable and nongradable images. Where the assumptions of normality were violated for continuous variables non-parametric techniques were be applied. Differences in proportions were assessed using Chi-squared tests. Binary outcome variables were analysed using logistic regression techniques. All the statistical tests were two-sided at the $5 \%$ significance level and effect size accompanied with $95 \%$ confidence interval $(95 \% \mathrm{CI})$.

\section{Results}

In total 3549 individuals participated in the initial study examination, corresponding to $56 \%$ of the eligible study population. Basic demographic information was available for all subjects within the sampling frame. There were four non-Caucasians in the $\geq 65$ year group who attended but were excluded from the study. Gender balance was similar for both attenders and non-attenders.

A total of 3475 (98\%) participants had gradable photographs, including a subset of $226(6 \%)$ with gradable images in one eye only. A total of $74(2 \%)$ individuals had ungradable images in both eyes.

Inter-observer variability was assessed using Kappa. Using the cut-offs proposed by Landis and Koch, ${ }^{35}$ there was substantial agreement of $76 \%$ between CARF and CW (kappa $=0.69$, SE 0.03, $P<0.001$ ), and excellent agreement of $86 \%$ between CW and WMA (kappa $=0.82$, 
Table 2a BEAP AMD grading: BEAP AMD grading results for right eye, left eye, and worse eye

\begin{tabular}{|c|c|c|c|c|}
\hline Grade & Right Eye (n (\%)) & Left Eye (n (\%)) & Worse Eye (n (\%)) & Best Eye (n (\%)) \\
\hline 0 & 1689 (50.57) & $1733(51.21)$ & 1337 (38.47) & 2195 (63.17) \\
\hline 1 & $1136(34.01)$ & 1115 (32.95) & 1440 (41.44) & 896 (25.78) \\
\hline 2 & 340 (10.18) & 339 (10.02) & 443 (12.75) & $255(7.34)$ \\
\hline 3 & 66 (1.98) & $90(2.66)$ & 97 (2.79) & 66 (1.90) \\
\hline $4 a$ & $66(1.98)$ & $63(1.86)$ & $85(2.45)$ & $48(1.38)$ \\
\hline $4 b$ & $38(1.14)$ & $40(1.18)$ & $64(1.84)$ & $15(0.43)$ \\
\hline $4 c$ & $5(0.15)$ & $4(0.12)$ & $9(0.26)$ & $0(0)$ \\
\hline Total & 3340 (100) & 3384 (100) & 3475 (100) & 3475 (100) \\
\hline$P$-value & \multicolumn{2}{|c|}{0.623} & \multicolumn{2}{|c|}{$<0.001$} \\
\hline
\end{tabular}

Table 2b BEAP AMD grading: sex distribution of worse eye Rotterdam AMD grade

\begin{tabular}{lcc}
\hline Grade & $\begin{array}{c}\text { Female }(\mathrm{n}(\text { Row \%; } \\
\text { Column \%) }\end{array}$ & $\begin{array}{c}\text { Male }(\mathrm{n}(\text { Row \% } \\
\text { Column \%) }\end{array}$ \\
\hline 0 & $733(54.8 ; 37.8)$ & $604(45.2 ; 39.32)$ \\
1 & $794(55.1 ; 40.95)$ & $646(44.9 ; 42.06)$ \\
2 & $259(58.5 ; 13.36)$ & $184(41.5 ; 11.98)$ \\
3 & $61(62.9 ; 3.15)$ & $36(37.1 ; 2.34)$ \\
$4 \mathrm{a}$ & $48(56.5 ; 2.48)$ & $37(43.5 ; 2.41)$ \\
$4 \mathrm{~b}$ & $38(59.4 ; 1.96)$ & $26(40.6 ; 1.69)$ \\
$4 \mathrm{c}$ & $6(66.7 ; 0.31)$ & $3(33.3 ; 0.2)$ \\
Total & $1939(55.8)$ & $1536(44.2)$ \\
\hline
\end{tabular}

SE $0.04, P<0.001)$. There was good agreement between graders across all AMD stages. The combined kappa for all 3 graders (CARF, CW, and WMA) for all categories was 0.71 . Prevalence rates were very similar between right and left eyes, as illustrated in Table $2 \mathrm{a}$ and did not differ between the genders. Prevalence rates for the worse eye were: $12.8 \%$ for grade 2 and $2.8 \%$ for grade 3; GA or nAMD (grade 4 AMD) had a prevalence of $4.6 \%$. For the worse eye, GA was more prevalent than nAMD, as shown in Table 2a. GA was 1.7 and 1.6 times more prevalent than $\mathrm{nAMD}$ in the right and left eyes respectively compared to 1.3 times for the worse eye (Table $2 \mathrm{a} ; P<0.001$ ). As shown in Table $2 \mathrm{~b}$, although $60 \%$ of prevalent cases of nAMD were in females, when adjusted, this prevalence was 2.0 and $1.7 \%$ for females and males, respectively. PPCNV (4c) was infrequent, with prevalence of $0.3 \%$ for the worse eye.

The prevalence of the earlier stages of ARM decreased with age (Table 3a). In subjects aged 65-69 years, 44.5\% had grade 0 AMD in their worse eye, but in subjects over 90 year age group only $15.2 \%$ had minimal or no evident morphological changes. There was a statistically significant increase in AMD prevalence with age from 65 years upwards $(P<0.001)$, as shown in Table 3a. In particular, there was a statistically significant difference in the prevalence of grade $4 \mathrm{a}$ and $4 \mathrm{~b}$ AMD across all age groups $(P<0.001)$. The prevalence of grade 4 AMD increased from $2.0 \%$ in the 65-69 year age group, to $15.9 \%$ for $85-90$ years, reaching a maximum of $21.2 \%$ in the $\geq 90$ years'. As the stage of AMD increased, the mean age of subjects with that stage of disease increased significantly ( $P<0.001$; for right, left or worse eye), as shown in Table 3b.

In this population, $64.5 \%$ of participants had the same grade of AMD in both eyes. There was a positive correlation of AMD grades between the two eyes of individual participants as indicated by Pearson's correlation coefficient of 0.5138 . This symmetry was especially notable at the lower grades of AMD. However, at the higher AMD grades significant asymmetry was observed between the two eyes of participants. GA was unilateral in $65.9 \%$, and bilateral in $34.1 \%$ participants. Similarly, bilateral nAMD was present in $21.9 \%$ of subjects, indicating that nAMD was more likely to be unilateral when compared to GA. Bilateral advanced $\operatorname{AMD}(4 \mathrm{a}, 4 \mathrm{~b}$, or $4 \mathrm{c})$ occurred in 63 people $(1.8 \%)$.

The proportion of the population with self-perceived dissatisfaction with vision is shown in Table 4a. As the grade of AMD increased the self-perceived dissatisfaction with vision worsened. A significant number of participants with the more advanced grades of AMD (61.0 and $40.6 \%$ of subjects with GA and nAMD, respectively) considered their vision to be satisfactory. In the early stages of ARM, the majority of subjects were happy with their vision, as shown in Table 4a. As the worse eye AMD grade increased, the percentage of subjects happy with their vision decreased from $77.9 \%$ (Grade 0) to $40.6 \%$ (grade $4 \mathrm{~b}$ ), the latter grade being the only stage at which the majority were dissatisfied with their vision. With the better eye, there was significant increase in subject dissatisfaction with vision, particularly for individuals with bilateral nAMD. Table $4 \mathrm{~b}$ demonstrates that individuals with grade $4 \mathrm{a}$ or $4 \mathrm{~b}$ AMD in their better eye were over four times more likely to report dissatisfaction with their vision when compared to individuals with no AMD.

As shown in Table 5, best spectacle or contact lens corrected VA (SCVA) was well maintained at LogMAR 
Table 3a Age distribution of AMD grades: age distribution by worse eye Rotterdam AMD score

\begin{tabular}{|c|c|c|c|c|c|c|c|}
\hline \multirow[t]{2}{*}{ AMD score } & \multicolumn{7}{|c|}{ Age (years) } \\
\hline & 65-69 (n (\%)) & $70-74(\mathrm{n}(\%))$ & 75-79 (n (\%)) & $80-84(\mathrm{n}(\%))$ & $85-90(\mathrm{n}(\%))$ & $\geq 90(\mathrm{n}(\%))$ & Total (\%) \\
\hline 0 & 378 (44.52) & $450(42.10)$ & $285(35.27)$ & 166 (31.14) & $53(28.96)$ & $5(15.15)$ & 1337 (38.47) \\
\hline 1 & $371(43.70)$ & $478(44.71)$ & 344 (42.57) & 189 (35.46) & $50(27.32)$ & $8(24.24)$ & 1440 (41.44) \\
\hline 2 & $70(8.24)$ & $105(9.82)$ & 111 (13.74) & 109 (20.45) & $39(21.31)$ & $9(27.27)$ & 443 (12.75) \\
\hline 3 & $11(1.30)$ & $15(1.40)$ & $25(3.09)$ & $30(5.63)$ & $12(6.56)$ & $4(12.12)$ & $97(2.79)$ \\
\hline $4 a$ & $9(1.06)$ & $16(1.50)$ & $21(2.60)$ & $18(3.38)$ & $18(9.84)$ & $3(9.09)$ & $85(2.45)$ \\
\hline $4 b$ & $8(0.94)$ & $4(0.37)$ & $19(2.35)$ & $19(3.56)$ & $10(5.46)$ & $4(12.12)$ & $64(1.84)$ \\
\hline $4 c$ & $2(0.24)$ & $1(0.09)$ & $3(0.37)$ & $2(0.38)$ & $1(0.55)$ & $0(0.00)$ & $9(0.26)$ \\
\hline Total & $849(100)$ & 1069 (100) & $808(100)$ & $533(100)$ & $183(100)$ & $33(100)$ & 3475 (100) \\
\hline$P$-value & $<0.001$ & & & & & & \\
\hline
\end{tabular}

Data are numbers (percentage within age categories).

Table $3 \mathbf{b}$ Age distribution of AMD grades: mean age distribution of Rotterdam grades

\begin{tabular}{|c|c|c|c|c|c|c|c|c|c|}
\hline \multirow[t]{2}{*}{ AMD grade } & \multicolumn{3}{|c|}{ Right eye } & \multicolumn{3}{|c|}{ Left eye } & \multicolumn{3}{|c|}{ Worse eye } \\
\hline & $\mathrm{N}$ & Mean (SE) & $95 \% C I$ & $\mathrm{~N}$ & Mean (SE) & $95 \% \mathrm{CI}$ & $\mathrm{N}$ & Mean (SE) & $95 \% C I$ \\
\hline 0 & 1689 & $73.9(0.13)$ & $73.6-74.2$ & 1733 & $74.2(0.13)$ & $73.9-74.4$ & 1337 & $74.1(0.15)$ & $73.8-74.4$ \\
\hline 1 & 1136 & $74.7(0.16)$ & $74.4-75.0$ & 1115 & $74.5(0.17)$ & $74.2-74.8$ & 1440 & $74.4(0.14)$ & $74.1-74.7$ \\
\hline 2 & 340 & $77.9(0.35)$ & $77.3-78.6$ & 339 & $77.6(0.34)$ & $77.0-78.3$ & 443 & $77.2(0.30)$ & $76.7-77.8$ \\
\hline 3 & 66 & $79.2(0.84)$ & $77.5-80.9$ & 90 & $79.4(0.74)$ & $77.9-80.8$ & 97 & $78.9(0.69)$ & $77.6-80.3$ \\
\hline $4 a$ & 66 & $79.9(0.84)$ & $78.2-81.6$ & 63 & $79.8(0.87)$ & $78.1-81.6$ & 85 & $79.5(0.75)$ & $78.0-81.0$ \\
\hline $4 b$ & 38 & $80.6(0.97)$ & $78.6-82.6$ & 40 & $79.4(1.06)$ & $77.3-81.6$ & 64 & $79.8(0.81)$ & $78.2-81.4$ \\
\hline $4 c$ & 5 & $76.2(2.90)$ & $68.1-84.2$ & 4 & $76.1(3.88)$ & $63.7-88.6$ & 9 & $76.1(2.20)$ & $71.1-81.2$ \\
\hline Total & 3340 & $74.9(0.10)$ & $74.7-75.1$ & 3384 & $74.9(0.10)$ & $74.7-75.1$ & 3475 & $75.0(0.10)$ & $74.8-75.2$ \\
\hline$P$-value & & $<0.001$ & & & $<0.001$ & & & $<0.001$ & \\
\hline 7 & 70 & $76.2(0.59)$ & $75.0-77.3$ & 46 & $77.2(0.83)$ & $75.5-78.9$ & & & \\
\hline 8 & 40 & $77.5(0.97)$ & $75.5-79.5$ & 36 & $77.8(1.08)$ & $75.6-80.0$ & & & \\
\hline 9 & 87 & $79.3(0.66)$ & $77.9-80.6$ & 71 & $78.4(0.79)$ & $76.8-80.0$ & & & \\
\hline
\end{tabular}

Table 4a Participant perception of vision: subject self-perception of vision as being satisfactory, with corresponding AMD grades

\begin{tabular}{lrrrr}
\hline AMD score & $\begin{array}{c}\text { Vision perceived as } \\
\text { satisfactory by study } \\
\text { subject worse eye vision }\end{array}$ & $\begin{array}{c}\text { Percentages not } \\
\text { satisfied with vision } \\
\text { stratified by better } \\
\text { eye grade }\end{array}$ \\
\cline { 2 - 3 } \cline { 5 - 5 } & No, N (\%) & Yes, N (\%) & N (\%) \\
\hline 0 & $291(22.06)$ & $1028(77.94)$ & $458(21.3)$ \\
1 & $286(20.30)$ & $1123(79.70)$ & $200(22.6)$ \\
2 & $116(26.36)$ & $324(73.64)$ & $76(30.0)$ \\
3 & $31(33.33)$ & $62(66.67)$ & $27(43.5)$ \\
4 a & $32(39.02)$ & $50(60.98)$ & $23(48.9)$ \\
4b & $38(59.38)$ & $26(40.62)$ & $13(86.7)$ \\
4c & $3(33.33)$ & $6(66.67)$ & $0(0)$ \\
Total & $797(23.33)$ & $2619(76.67)$ & \\
$P$-value & $<0.001^{\text {a }}$ & \\
\hline
\end{tabular}

aPearson Chi-Square.

0.3 (Snellen 6/12) or better for most eyes through the early stages of ARM (AMD grade $\leq 2$ ). In eyes with GA, vision was maintained at LogMAR 0.3 or better for $36.4 \%$ and $41.3 \%$ of right and left eyes, respectively. There was widespread variation in vision, ranging from excellent (LogMAR 0.0) to counting fingers, depending on the exact location of the degeneration in eyes with GA. Eyes with nAMD were most likely to suffer significant visual impairment, with $57.9 \%$ and $55.0 \%$ of right and left eyes respectively having SCVA of LogMAR 1.0 or worse. Only a small minority of subjects with nAMD (10 and 5\%) maintained a good SCVA in the right and left eyes respectively. BCVA positively correlated between the two eyes in most participants (Pearson's coefficient $=0.5562$, $P<0.001)$. There was significant asymmetry of BCVA between the two eyes in some participants which correlated with the grade of AMD (Kruskall-Wallis, $P<0.001)$. There was no association of AMD grade with gender $(P=0.55)$, the presence of diagnosed hypertension $(P=0.513)$, or diabetes mellitus $(P=0.882)$. A history of a previous stroke did not reach statistical significance for the left eye $(P=0.055)$, or the right eye $(P=0.318)$.

The relationship between AMD and cataract was explored with linear and logistic regression models using the grade of nuclear cataract and the presence of significant cataract as the respective dependent variables. 
Table $4 \mathbf{b}$ Participant perception of vision: odds ratios for dissatisfaction with vision when compared to subjects with grade $0 \mathrm{a} / 0 \mathrm{~b}$

\begin{tabular}{|c|c|c|c|c|c|c|}
\hline \multirow[t]{3}{*}{ AMD grade } & \multirow{2}{*}{\multicolumn{2}{|c|}{$\frac{\text { Crude unadjusted odds ratio }}{\text { Better eye }}$}} & \multicolumn{4}{|c|}{ Logistic regression model } \\
\hline & & & \multicolumn{2}{|c|}{$\begin{array}{c}\text { Better eye adjusted for age } \\
\text { and significant cataract }\end{array}$} & \multicolumn{2}{|c|}{$\begin{array}{c}\text { Worse eye adjusted for age } \\
\text { and significant cataract }\end{array}$} \\
\hline & Odds ratio $(95 \% \mathrm{CI})$ & P-value & Odds ratio $(95 \% \mathrm{CI})$ & P-value & Odds ratio & P-value \\
\hline 0 & 1.00 & & 1.00 & & 1.00 & \\
\hline 1 & $1.08(0.90-1.31)$ & 0.40 & $1.06(0.87-1.28)$ & 0.58 & $0.90(0.75-1.09)$ & 0.28 \\
\hline 2 & $1.59(1.19-2.12)$ & 0.00 & $1.38(1.02-1.86)$ & 0.04 & $1.17(0.90-1.51)$ & 0.23 \\
\hline 3 & $2.86(1.71-4.78)$ & 0.00 & $2.49(1.48-4.22)$ & 0.00 & $1.56(0.98-2.46)$ & 0.06 \\
\hline 4 & $5.13(3.05-8.63)$ & 0.00 & $4.35(2.57-7.35)$ & 0.00 & $2.73(1.92-3.88)$ & 0.00 \\
\hline Visually significant cataract ${ }^{\mathrm{a}}$ & $1.31(1.11-1.55)$ & 0.00 & $1.30(1.10-1.54$ & 0.00 & & \\
\hline Age (per year increase) & $1.02(1.01-1.04)$ & 0.00 & $1.03(1.01-1.04$ & 0.00 & & \\
\hline
\end{tabular}

avisually significant cataract was defined as LOCS 3 nuclear sclerosis $\geq 4$ or cortical cataract $\geq 3$ or posterior subcapsular cataract $\geq 2$ or evidence of previous surgery.

Table 5 Summary of spectacle corrected visual acuity (SCVA) for right and left eyes across AMD grades, subcategorised for level of visual impairment

\begin{tabular}{|c|c|c|c|c|c|c|c|c|}
\hline \multirow[t]{2}{*}{ Rotterdam Grade } & \multicolumn{3}{|c|}{ Right eye SCVA } & \multirow{2}{*}{$\begin{array}{c}\text { Total } \\
(n(\%))\end{array}$} & \multicolumn{3}{|c|}{ Left eye } & \multirow{2}{*}{$\begin{array}{c}\text { Total } \\
(n(\%))\end{array}$} \\
\hline & $\begin{array}{l}\text { Good vision } \\
(\mathrm{n}(\%))\end{array}$ & $\begin{array}{l}\text { Low vision } \\
(\mathrm{n}(\%))\end{array}$ & $\begin{array}{c}\text { Poor vision } \\
\text { (n (\%)) }\end{array}$ & & $\begin{array}{c}\text { Good vision } \\
(n(\%))\end{array}$ & $\begin{array}{c}\text { Low vision } \\
(n(\%))\end{array}$ & $\begin{array}{c}\text { Poor vision } \\
(n(\%))\end{array}$ & \\
\hline 0 & $1257(74.4)$ & $416(24.6)$ & $16(0.95)$ & $1689(100)$ & 1267 (73.1) & 439 (25.3) & 27 (1.6) & $1733(100)$ \\
\hline 1 & $852(75)$ & $280(24.7)$ & $4(0.35)$ & $1136(100)$ & 833 (74.7) & $268(24.0)$ & $14(1.3)$ & 1115 (100) \\
\hline 2 & $213(62.7)$ & $123(36.2)$ & $4(1.2)$ & $340(100)$ & $222(65.5)$ & $113(33.3)$ & 4 (1.2) & 339 (100) \\
\hline 3 & $28(42.4)$ & 38 (57.6) & $0(0.0)$ & $66(100)$ & $48(53.3)$ & $40(44.4)$ & $2(2.2)$ & $90(100)$ \\
\hline $4 a$ & $24(36.4)$ & $30(45.5)$ & $12(18.2)$ & $66(100)$ & $26(41.3)$ & $27(42.9)$ & $10(15.9)$ & $63(100)$ \\
\hline $4 b$ & $4(10.5)$ & 12 (31.6) & $22(57.9)$ & $38(100)$ & $2(5.0)$ & $16(40.0)$ & $22(55.0)$ & $40(100)$ \\
\hline $4 c$ & $3(60.0)$ & $2(40.0)$ & $0(0.0)$ & $5(100)$ & $1(25.0)$ & $3(75.0)$ & $0(0.0)$ & $4(100)$ \\
\hline Total & $2381(71.3)$ & $901(27.0)$ & $58(1.74)$ & $3340(100)$ & 2399 (70.9) & $906(26.8)$ & $79(2.3)$ & $3384(100)$ \\
\hline
\end{tabular}

SCVA subgroups: Good Vision =SCVA Log MAR 0.3 or better, low vision =SCVA between Log MAR 0.3 and Log MAR 1.0 and poor vision =SCVA of Log MAR 1.0 or worse. Data are numbers (row percentage).

Significant cataract was defined as LOCS III nuclear sclerosis $\geq 4$, or cortical cataract $\geq 3$, posterior subcapsular cataract $\geq 2$, or evidence of previous surgery. A weak association between AMD and cataract was found $(P<0.001)$, which disappeared when age was included as a covariate (right eyes $P=0.062$, left eyes $P=0.07$ ).

Supplementary Results are provided in Online Supplementary.

\section{Discussion}

This is the largest UK population-based study of AMD in the $\geq 65$ year age group to date, and includes a large number of participants aged $\geq 80$ year age, representing a scarce resource among published UK population studies, where older subgroups tend to be small. ${ }^{25,26,36}$ Quality assurance through secondary grading was carried out by an established reading centre. The study utilised digital fundus photography and grading methods that are well-recognised and used in previous population based studies. ${ }^{11,37}$ Image grading was masked, and mydriatic fundus photography obviated the disadvantages of nonmydriatic photography, ${ }^{16,29}$ which could hamper grading, particularly of early ARM.

The measured prevalence of advanced AMD (grade 4) in this $\geq 65$ year population of $4.6 \%$ is higher than reported in several UK studies, including the EUREYE ( $3.77 \%$ in the Belfast arm) and the Speedwell eye study $(0.5 \%)$, but similar to $4.8 \%$ derived from the Owen analysis of 2012..25 This is despite the exclusion of participants who were registered as visually impaired (VI) and severely visually impaired (SVI). As such, a significant number of persons with bilateral advanced AMD may have been excluded. This implies that our reported prevalence of advanced AMD (grade 4), despite being higher than previously reported, may actually be an underestimation. In the BEAP study, several participants had reduced vision bilaterally but were not registered as 
VI. This finding suggests that at the time of this project VI/SVI registration data may have been incomplete in the Bridlington area. Nevertheless, the prevalence rates of AMD in this BEAP study are generally higher than previously reported in similar age subgroupings in other studies, $7,9-14,16$ and may be related to the larger participation of the older population than in previous studies, or higher detection rates.

To the best of our knowledge, this study provides for the first time, the population prevalence for grade $4 \mathrm{c}$ AMD in the UK, and data on the prevalence of early stages of AMD and persons with asymmetric AMD. There is a significant proportion of the population who have advanced AMD in one eye, while the other eye functions normally. Such persons are not captured by current methods of visual impairment data collection in the UK. Similarly, persons with the earlier and intermediate stages of AMD are asymptomatic, and can only be detected by regular checks. Such information is necessary for health care planning.

A common finding among previous prevalence studies in populations of, or derived from European ancestry was that nAMD was more common than GA.7,9-11 The TILDA Study showed that GA and nAMD had similar prevalence in the Irish population of $\geq 50$ years, although their figures were significantly lower than in our study, possibly reflecting the utilisation of non-mydriatic photography, making acquisition of clear images difficult in the presence of media opacities. ${ }^{16}$ Our findings indicate that the prevalence of GA is not less common than nAMD in either eye. This difference remained for the worse eye, with GA being 1.3 times more common than nAMD, similar to that reported elsewhere, typically in Iceland. ${ }^{13,38}$ Jonasson et al ${ }^{13}$ in the Reykjavik Eye Study reported that atrophic AMD and nAMD occurred in 9.2\% and $2.4 \%$, respectively in individuals over 70 years of age. ${ }^{13}$ In the Greenland Inuit Eye Study ${ }^{39}$ this finding was not repeated as GA occurred in one or both eyes in $2.3 \%$, nAMD in one or both eyes in $6.1 \%$, and GA in one eye and $\mathrm{nAMD}$ in the other eye in $1.1 \%$ of the 695 participants aged 60 years or over. The nature and significance of these differences is uncertain but could reflect genetic factors which have been reported to play a role in the prevalence of AMD. ${ }^{40-42}$ Other explanations include the misclassification of chronic PEDs associated with areas of GA (potentially secondary to the utilisation of nonstereoscopic photography) or previous laser photocoagulation in the macular area. Our re-evaluation of images, however, excluded the possibility of misclassification or confounding with previous laser treatment and/or history of diabetes in eyes with GA.

The self-reported satisfaction with participants' vision is interesting. It shows that a large proportion of individuals with GA in their worse eye remained satisfied with their vision. With regards to the worse eye, nAMD is the only stage at which the majority of participants are dissatisfied, while with the better eye, subject dissatisfaction with vision increased, particularly for individuals with bilateral nAMD.

Our results are highly likely representative of the Caucasian population studied. Attendance rates are lower than in some studies, $7,9,11,13$ probably reflecting the older age of inclusion in our study, but largely comparable to those in others, $, 8,10,12,16,43$ considering that many of these latter studies used lower minimum age inclusions. Allowing home examination may have increased our response rate but would have reduced the degree of standardisation of procedures and grading, through exclusion of photography.

A limitation of the current study is that the use of non-stereoscopic photographs could have resulted in an underestimation of the prevalence of nAMD by missing subtle PEDs. However, chronic PEDs with significant activity from a CNV would likely be associated with other signs including retinal haemorrhages or gliosis, which would have allowed their identification. Furthermore, as this study excluded persons registered as visually impaired, a significant number of patients with bilateral advanced AMD may have been excluded resulting in an underestimation of true prevalence.

Another limitation is that the population was purely Caucasian, and does not provide any information on racial differences in AMD in the UK. However, this is also strength, as a similar sized study of a mixed population would have wider confidence limits for each finding in each racial group.

The limitation of utilising colour photographs as the only imaging modality in this study is obvious, as the early stages of AMD may be overlooked, where optical coherence tomography and autofluorescence images are not available. Similarly reticular pseudodrusen may be difficult to detect without multimodal imaging. Despite such potential under-estimation, the technology and grading system used is similar to that in previous AMD population studies, and should therefore yield comparable reliability.

In conclusion, this study provides contemporary prevalence rates of different stages of AMD in a UK population, and indicates that the prevalence of advanced AMD is more common than previously thought. It has also, for the first time, provided data on the occurrence of AMD asymmetry in the population. Further studies are required in other UK communities to determine differences in prevalence amongst the different ethnicities, as well as determine incidence rates. 


\section{Summary}

What was known before

- There is paucity of data on the prevalence of age-related macular degeneration (AMD) in the UK, and the existing data is based on certification for visual impairment, or limited population samples.

- No data is available for disease asymmetry or the early asymptomatic stages of AMD, for the UK population.

What this study adds

- This represents the largest UK population study of AMD.

- Neovascular AMD and geographic atrophy (advanced AMD) occurred more commonly $(1.8 \%$ and $2.5 \%$, respectively) in the UK Caucasian population $\geq 65$ years old than previously reported.

- There is significant asymmetry between the two eyes in some individuals with advanced AMD in one eye so that visual impairment statistics alone do not represent a true prevalence of advanced AMD.

- Patients with more advanced AMD are more likely to be dissatisfied with their vision.

\section{Conflict of interest}

Winfried M Amoaku: Consultant for Alimera, Allergan Inc, Bayer, Novartis, Pfizer, Santen, and Thrombogenics, and has undertaken research sponsored by Allergan, Novartis, and Pfizer. He has received speaker fees and travel grants from Allergan, Bausch and Lomb, Bayer, Novartis and Pfizer. Stephen A Vernon: Consultant for Allergan and Alcon, and has undertaken research sponsored by Allergan and Pfizer. He has received speaker fees from Allergan, Alcon, Pfizer, Optivue and Topcon. The remaining authors declare no conflict of interest.

\section{Acknowledgements}

This research was funded in part by a Research Grant from the Macular Society UK, Andover, Hants, UK. The Bridlington Eye Assessment Project was funded by an unrestricted grant from Pfizer. We would also like to thank the following organisations for financial support of the Project: Pharmacia, Yorkshire Wolds and Coast Primary Care Trust, The Lords Feoffees of Bridlington, Bridlington Hospital League of Friends, The Hull and East Riding Charitable Trust, The National Eye Research Centre (Yorkshire), The Rotary Club of Bridlington, The Alexander Pigott Wernher Memorial Trust, Bridlington Lions Club, The Inner Wheel Club of Bridlington, Soroptimist International of Bridlington, and The Patricia and Donald Shepherd Charitable Trust. We would also like to thank Sheila MacNab (Project Manager), and Stephen Brown, Janet Button, Graham Langton, and Mark Kunz (Optometrists) for their work with the Project; John
Bapty, Nigel Connell, Peter Jay, and Gillian Poole for their work as the charity trustees of the Bridlington Eye Assessment Project.

\section{References}

1 Congdon N, O'Colmain B, Klaver CC, Klein R, Muñoz B, Friedman DS et al. Causes and prevalence of visual impairment among adults in the United States. Arch Ophthalmol 2004; 122: 477-485.

2 Resnikoff S, Pascolini D, Etya'ale D, Kocur I, Pararajasegaram R, Pokharel GP et al. Global data on visual impairment in the year 2002. Bull World Health Organ 2004; 82: 844-851.

3 Gass JD. Drusen and disciform macular detachment and degeneration. Arch Ophthalmol 1973; 90: 206-217.

4 Klein ML, Ferris FL 3rd, Armstrong J, Hwang TS, Chew EY, Bressler SB et al. Retinal precursors and the development of geographic atrophy in age-related macular degeneration. Ophthalmology 2008; 115: 1026-1031.

5 van Leeuwen R, Klaver CC, Vingerling JR, Hofman A, de Jong PT. The risk and natural course of age-related maculopathy: follow-up at $61 / 2$ years in the Rotterdam study. Arch Ophthalmol 2003; 121: 519-526.

6 Minassian DC, Reidy A, Lightstone A, Desai P. Modelling the prevalence of age-related macular degeneration (2010-2020) in the UK: expected impact of anti-vascular endothelial growth factor (VEGF) therapy. Br J Ophthalmol 2011; 95: 1433-1436.

7 Mitchell P, Smith W, Attebo K, Wang JJ. Prevalence of age-related maculopathy in Australia. The Blue Mountains Eye Study. Ophthalmology 1995; 102: 1450-1460.

8 VanNewkirk MR, Nanjan MB, Wang JJ, Mitchell P, Taylor HR, McCarty CA. The prevalence of age-related maculopathy: the visual impairment project. Ophthalmology 2000; 107(8): 1593-1600.

9 Klein R, Klein BE, Linton KL. Prevalence of age-related maculopathy. The Beaver Dam Eye Study. Ophthalmology 1992; 99: 933-943.

10 Vingerling JR, Dielemans I, Hofman A, Grobbee DE, Hijmering M, Kramer CF et al. The prevalence of age-related maculopathy in the Rotterdam Study. Ophthalmology 1995; 102: 205-210.

11 Augood CA, Vingerling JR, de Jong PT, Chakravarthy U, Seland J, Soubrane G et al. Prevalence of age-related maculopathy in older Europeans: the European Eye Study (EUREYE). Arch Ophthalmol 2006; 124(4): 529-535.

12 Korb CA, Kottler UB, Wolfram C, Hoehn R, Schulz A, Zwiener I et al. Prevalence of age-related macular degeneration in a large European cohort: results from the population-based Gutenberg Health Study. Graefe Arch Clin Exp Ophthalmol 2014; 252: 1403-1411.

13 Jonasson F, Arnarsson A, Sasaki H, Peto T, Sasaki K, Bird AC. The prevalence of age-related maculopathy in Iceland: Reykjavik eye study. Arch Ophthalmol 2003; 121: 379-385.

14 Pagliarini S, Moramarco A, Wormald RP, Piguet B, Carresi C, Balacco-Gabrieli C et al. Age-related macular disease in rural southern Italy. Arch Ophthalmol 1997; 115: 616-622.

15 Laatikainen L, Hirvela H. Prevalence and visual consequences of macular changes in a population aged 70 years and older. Acta Ophthalmol Scand 1995; 73: 105-110. 
16 Akuffo KO, Nolan J, Stack J, Moran R, Feeney J, Kenny RA et al. Prevalence of age-related macular degeneration in the Republic of Ireland. Br J Ophthalmol 2015; 99: 1037-1044.

17 Krishnan T, Ravindran RD, Murthy GV, Vashist P, Fitzpatrick KE, Thulasiraj RD et al. Prevalence of early and late age-related macular degeneration in India: the INDEYE study. Invest Ophthalmol Vis Sci 2010; 51: 701-707.

18 Li Y, Xu L, Jonas JB, Yang H, Ma Y, Li J. Prevalence of age-related maculopathy in the adult population in China: the Beijing eye study. Am J Ophthalmol 2006; 142: 788-793.

19 Oshima Y, Ishibashi T, Murata T, Tahara Y, Kiyohara Y, Kubota T. Prevalence of age related maculopathy in a representative Japanese population: the Hisayama study. Br J Ophthalmol 2001; 85: 1153-1157.

20 Schachat AP, Hyman L, Leske MC, Connell AM, Wu SY. Features of age-related macular degeneration in a black population. The Barbados Eye Study Group. Arch Ophthalmol 1995; 113: 728-735.

21 Rudnicka AR, Jarrar Z, Wormald R, Cook DG, Fletcher A, Owen CG. Age and gender variations in age-related macular degeneration prevalence in populations of European ancestry: a meta-analysis. Ophthalmology 2012; 119: 571-580.

22 Bunce C, Xing W, Wormald R. Causes of blind and partial sight certifications in England and Wales: April 2007-March 2008. Eye 2010; 24: 1692-1699.

23 Barry RJ, Murray PI. Unregistered visual impairment: is registration a failing system? Br J Ophthalmol 2005; 89: 995-998.

24 Owen CG, Fletcher AE, Donoghue M, Rudnicka AR. How big is the burden of visual loss caused by age related macular degeneration in the United Kingdom? $\mathrm{Br} J$ Ophthalmol 2003; 87: 312-317.

25 Owen CG, Jarrar Z, Wormald R, Cook DG, Fletcher AE, Rudnicka AR. The estimated prevalence and incidence of late stage age related macular degeneration in the UK. $\mathrm{Br} J$ Ophthalmol 2012; 96: 752-756.

26 Evans JR, Fletcher AE, Wormald RP. Age-related macular degeneration causing visual impairment in people 75 years or older in Britain: an add-on study to the Medical Research Council Trial of Assessment and Management of Older People in the Community. Ophthalmology 2004; 111: 513-517.

27 Gibson JM, Rosenthal AR, Lavery J. A study of the prevalence of eye disease in the elderly in an English community. Trans Ophthalmol Soc UK 1985; 104: 196-203.

28 Reidy A, Minassian DC, Vafidis G, Joseph J, Farrow S, Wu J. Prevalence of serious eye disease and visual impairment in a north London population: population based, cross sectional study. BMJ 1998; 316(7145): 1643-1646.

29 Yip JL, Khawaja AP, Chan MP, Broadway DC, Peto T, Luben R et al. Area deprivation and age related macular degeneration in the EPIC-Norfolk Eye Study. Public Health 2015; 129: 103-109.

30 Dickinson AJ, Sparrow JM, Duke AM, Thompson JR, Gibson JM, Rosenthal AR. Prevalence of age-related maculopathy at two points in time in an elderly British population. Eye 1997; 11: 301-314.
31 Ngai LY, Stocks N, Sparrow JM, Patel R, Rumley A, Lowe G et al. The prevalence and analysis of risk factors for age-related macular degeneration: 18-year follow-up data from the Speedwell eye study, United Kingdom. Eye 2011; 25: 784-793.

32 Vernon SA, Hawker MJ, Ainsworth G, Hillman JG, Macnab HK, Dua HS. Laser scanning tomography of the optic nerve head in a normal elderly population: the Bridlington eye assessment project. Invest Ophthalmol Vis Sci 2005; 46: 2823-2828.

33 Bird AC, Bressler NM, Bressler SB, Chisholm IH, Coscas G, Davis MD et al. An international classification and grading system for age-related maculopathy and age-related macular degeneration. The International ARM Epidemiological Study Group. Surv Ophthalmol 1995; 39: 367-374.

34 Klaver CC, Assink JJ, van Leeuwen R, Wolfs RC, Vingerling JR, Stijnen T et al. Incidence and progression rates of age-related maculopathy: the Rotterdam Study. Invest Ophthalmol Vis Sci 2001; 42: 2237-2241.

35 Landis JR, Koch GG. The measurement of observer agreement for categorical data. Biometrics 1977; 33: 159-174.

36 Bunce C, Wormald R. Causes of blind certifications in England and Wales: April 1999-March 2000. Eye (Lond) 2008; 22: 905-911.

37 van Leeuwen $\mathrm{R}$, Chakravarthy $\mathrm{U}$, Vingerling JR, Brussee C, Hooghart AJ, Mulder PG et al. Grading of age-related maculopathy for epidemiological studies - Is digital imaging as good as 35-mm film? Ophthalmology 2003; 110: 1540-1544.

38 Jonasson F, Thordarson K. Prevalence of ocular disease and blindness in a rural area in the eastern region of Iceland during 1980 through 1984. Acta Ophthalmol Suppl 1987; 182: 40-43.

39 Andersen MV, Rosenberg T, la Cour M, Kiilgaard JF, Prause JU, Alsbirk PH et al. Prevalence of age-related maculopathy and age-related macular degeneration among the Inuit in Greenland. The Greenland Inuit Eye Study. Ophthalmology 2008; 115: 700-707.

40 Klein ML, Schultz DW, Edwards A, Matise TC, Rust K, Berselli CB et al. Age-related macular degeneration. Clinical features in a large family and linkage to chromosome 1q. Arch Ophthalmol 1998; 116: 1082-1088.

41 Weeks DE, Conley YP, Tsai HJ, Mah TS, Rosenfeld PJ, Paul TO et al. Age-related maculopathy: an expanded genome-wide scan with evidence of susceptibility loci within the $1 \mathrm{q} 31$ and 17q25 regions. Am J Ophthalmol 2001; 132: 682-692.

42 Baird PN, Hageman GS, Guymer RH. New era for personalized medicine: the diagnosis and management of age-related macular degeneration. Clin Exp Ophthalmol 2009; 37: 814-821.

43 Bressler NM, Bressler SB, West SK, Fine SL, Taylor HR. The grading and prevalence of macular degeneration in Chesapeake Bay watermen. Arch Ophthalmol 1989; 107: 847-852.

Supplementary Information accompanies this paper on Eye website (http://www.nature.com/eye) 